\title{
Molecular characterization of Sp serotype strains of infectious pancreatic necrosis virus exhibiting differences in virulence
}

\author{
R. B. Shivappa ${ }^{1}$, H. Song ${ }^{1}$, K. Yao ${ }^{1,4}$, A. Aas-Eng ${ }^{2}$, Ø. Evensen $^{3}$, V. N. Vakharia ${ }^{1, *}$ \\ ${ }^{1}$ Center for Biosystems Research, University of Maryland Biotechnology Institute and VA-MD Regional College of \\ Veterinary Medicine, University of Maryland, College Park, Maryland 20742, USA \\ ${ }^{2}$ Alpharma, Animal Health Division, PO Box 158, Skøyen, 0212 Oslo, Norway \\ ${ }^{3}$ Department of Basic Sciences and Aquatic Medicine, Norwegian School of Veterinary Science, PO Box 8146 Department, \\ 0033 Oslo, Norway \\ ${ }^{4}$ Present address: Wyeth-Lederle Vaccine and Pediatrics, PO Box 304, Marietta, Pennsylvania 17547, USA
}

\begin{abstract}
Infectious pancreatic necrosis virus (IPNV), a prototype virus of the family Birnaviridae, exhibits a high degree of antigenic variability, pathogenicity and virulence in salmonid species. The Genomic Segment A encodes all the structural (VP2 and VP3) and nonstructural (NS) proteins, whereas Segment B encodes the viral RNA-dependent RNA polymerase (VP1). We tested 3 different IPNV isolates (Sp103, Sp116 and Sp122) isolated during field outbreaks in Norway for their ability to cause mortality in fry and post-smolt of Atlantic salmon Salmo salar L. The cumulative mortality following experimental challenge in fry was 29\% for Sp122 followed by $19 \%$ for Sp116 and $15 \%$ for Sp103. In post-smolt, the corresponding mortality rates were 79,46 and $16 \%$, respectively. Comparisons of the deduced amino acid sequences of Segments A and B of all $3 \mathrm{Sp}$ strains revealed substitutions of residues in 13 positions, of which 6 are in VP2, 2 in VP3, and 5 in VP1. Our results suggest that these residues, especially those in the outer capsid VP2, may be involved in the virulence of IPNV. Genome Segment A of the Sp serotype is 3097 nucleotides long and contains a major open reading frame (ORF) encoding a polyprotein of 972 amino acids, which initiates at the second inframe start codon at Position 119. This was ascertained by making mutants of Segment A clone using site-directed mutagenesis, followed by in vitro transcription-coupled translation reaction and immunoprecipitation analyses. In addition, Segment A also encodes a $15 \mathrm{kDa}$ arginine-rich nonstructural protein from a small ORF, preceding and partially overlapping the polyprotein ORF, which is truncated to $12 \mathrm{kDa}$ in the virulent Sp122 strain. Moreover, Segment A could encode a novel, putative $25 \mathrm{kDa}$ protein from another ORF between VP2 and VP4 coding regions, which is only detected in the Sp serotype. Segment B is 2777 nucleotides long and encodes in a single large ORF (a polypeptide of 844 amino acid residues), VP1.
\end{abstract}

KEY WORDS: Infectious pancreatic necrosis virus · IPNV $\cdot$ Sp serotype $\cdot$ Virulence $\cdot$ Molecular characterization

Resale or republication not permitted without written consent of the publisher

\section{INTRODUCTION}

Salmo salar aquaculture has attracted great interest in recent years due to the increasing demand for this high-value species. The intensity at which fish are reared and the other complexities involved in an aqua- culture system make the cultured species highly susceptible to various diseases. Infectious pancreatic necrosis virus (IPNV) is one of the major pathogens that bring about huge economic losses in the high-density salmon rearing systems. IPNV causes a highly contagious and destructive disease in juveniles of rainbow 
and brook trout as well as Atlantic salmon (Wolf 1988). An outbreak of IPNV can destroy an entire aquaculture operation and the surviving fish become lifelong carriers (Knott \& Munro 1986). In Norway, a loss of about 60 million US dollars annually due to IPNV infection alone has been reported (Christie 1997).

IPNV belongs to the genus Aquabirnavirus of the family Birnaviridae (Dobos 1995a, Leong et al. 2000). The genome of IPNV consists of 2 segments of doublestranded RNA that are enclosed within a singleshelled, icosahedral capsid measuring $60 \mathrm{~nm}$ in diameter (Dobos 1976). Segment A (3097 bp) encodes a $106 \mathrm{kDa}$ precursor protein in a single large open reading frame (ORF) that is cotranslationally cleaved by the viral nonstructural (NS) protease, VP4, to generate mature VP2 and VP3 structural proteins (Duncan \& Dobos 1986, Duncan et al. 1987). Precise cleavage sites between the VP2-VP4 and VP4-VP3 junctions of the polyprotein have been identified (Petit et al. 2000). In addition, Segment A encodes a $17 \mathrm{kDa}$ arginine-rich NS protein from a small ORF (also known as VP5), which precedes and partially overlaps the polyprotein ORF (Magyar \& Dobos 1994). This protein has been detected in virus-infected cells (Magyar \& Dobos 1994) but it is not required for replication (Weber et al. 2001). Segment B encodes a $94 \mathrm{kDa}$ protein, VP1, which is the virion-associated RNAdependent RNA polymerase (Duncan et al. 1991, Dobos 1995b). VP1 is found both as a free polypeptide and as a genome-linked protein, VPg, which is attached to the $5^{\prime}$-end of segments A and B (Calvert et al. 1991). Using synthetic transcripts derived from cloned Segments A and B, a reverse-genetics system for IPNV was first developed by Yao \& Vakharia (1998).

There are 2 distinct serogroups of IPNV, designated as Serogroups A and B. Serogroup A comprises 9 serotypes that are pathogenic to fishes, whereas Serotype B comprises 1 serotype isolated from molluscs (Leong \& Fryer 1993, Hill \& Way 1995). Within the 9 serotypes, there is a high degree of antigenic variability, and differences in the virulence and pathogenicity among the strains. Sp serotype strains are predominant in Europe, whereas the West Buxton (WB) strain is more prevalent in the United States. Since virulence of IPNV has been associated with Segment A (Sano et al. 1992), there may be differences at the molecular level within Segment A that makes the closely related isolates of IPNV so varied in their virulence. Recently, Bruslind \& Reno (2000) identified 2 amino acid differences within the VP2 region of a virulent and avirulent Buhl strain of IPNV that was used to infect brook trout fry. However, there are no reports regarding the virulence of Sp serotype of IPNV.

Therefore, to identify the molecular determinants of varying virulence in IPNV, we completely character- ized the Genomic Segments A and B of 3 Sp field isolates, Sp103, Sp116 and Sp122, which caused 16, 46 and $79 \%$ mortality in Atlantic salmon Salmo salar L. post-smolts, respectively. A lower but identical pattern of mortality was found in fry challenge of the same species. In this report, we describe the cloning and sequencing of genomic segments of these viruses, including 5'- and 3 '-noncoding regions, and identification of putative amino acids involved in the virulence of IPNV. Furthermore, we analyzed the initiation of the polyprotein coded by the major ORF and detection of a putative $25 \mathrm{kDa}$ protein from an overlapping ORF that has not been reported earlier.

\section{MATERIALS AND METHODS}

Cells and viruses. Chinook salmon embryo cells (CHSE-214 ATCC CRL-1681) were maintained at $15^{\circ} \mathrm{C}$ in minimal essential medium containing Hanks' salts supplemented with $10 \%$ fetal bovine serum (FBS). We collected 3 Sp isolates, Sp103, Sp116 and Sp122, from field outbreaks of IPNV in NW Norway in 1998. These viruses were propagated in CHSE cells and purified as described previously by Chang et al. (1978). Briefly, CHSE cells were infected with the viruses, and after the cytopathic effect was observed, the cells were scraped into the medium and the crude virus was clarified by centrifuging at $5000 \times g$ for $30 \mathrm{~min}$ at $4^{\circ} \mathrm{C}$. The pellet was resuspended in $15 \mathrm{ml} \mathrm{HO}$ buffer $(0.01 \mathrm{M}$ Tris- $\mathrm{HCl}$, $0.25 \mathrm{M} \mathrm{NaCl}, 0.01 \mathrm{M} \beta$-mercaptoethanol), mixed with $1 \mathrm{vol}$ of Freon, and homogenized for $15 \mathrm{~min}$ at $5000 \times g$ for $30 \mathrm{~min}$ at $4^{\circ} \mathrm{C}$ (Sorvall HB-4 rotor). The supernatant was aspirated and loaded carefully on a $26 \%$ sucrose cushion and subjected to ultracentrifugation at $120000 \mathrm{~g}$ for $2 \mathrm{~h}$ at $4^{\circ} \mathrm{C}$. Finally, the virus pellet was resuspended in $500 \mu \mathrm{l}$ of $\mathrm{HO}$ buffer and stored at $-20^{\circ} \mathrm{C}$ until use.

For the challenge studies, supernatants from cells exhibiting more than $80 \%$ CPE (cytopathic effect) were collected, titrated by plaque assay, and stored at $4^{\circ} \mathrm{C}$ for a maximum of $1 \mathrm{wk}$ before use.

Post-smolt challenge. The experiment was run at the VESO Vikan AkvaVet facility, Namsos, Norway. Atlantic salmon post-smolts that had gone through light and temperature-induced smoltification were challenged with the second passage from infected CHSE cells of 3 different $\mathrm{Sp}$ isolates by immersion in three $0.6 \mathrm{~m}$ tanks: 100 fish in each tank and 1 duplicate for each isolate. IPNV-free fish with an average weight of $39 \mathrm{~g}$ were challenged $1 \mathrm{~d}$ after transfer to seawater with a salinity of 30 to $32 \%$. The water-quality parameters were maintained at optimum levels and the experiment was run at $10 \pm 1^{\circ} \mathrm{C}$. Groups of fish were challenged with Sp103, Sp116 or Sp122 virus, and a group of fish (control) was not challenged but other- 


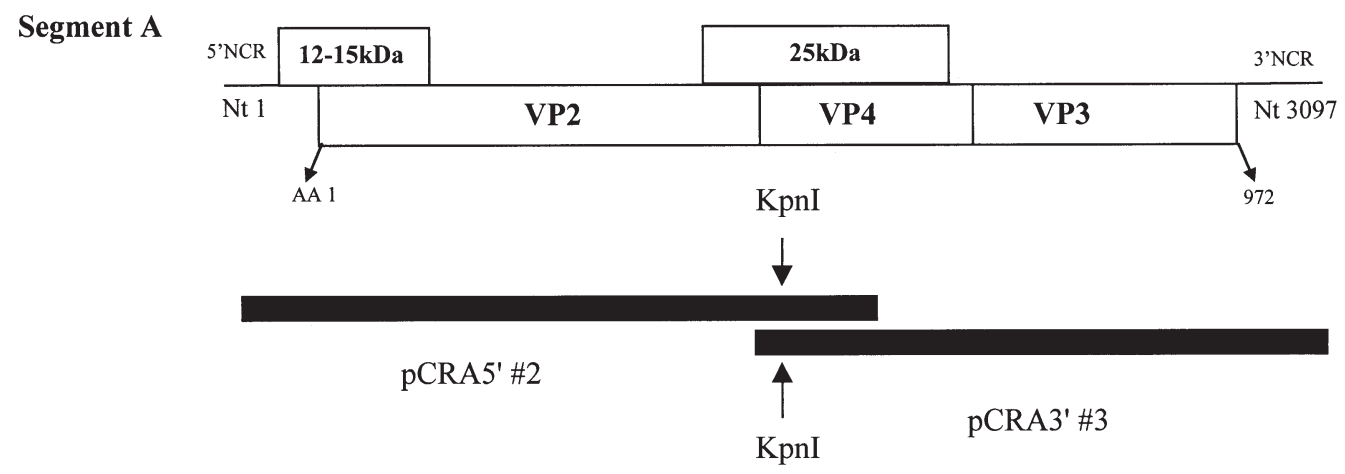

Segment B

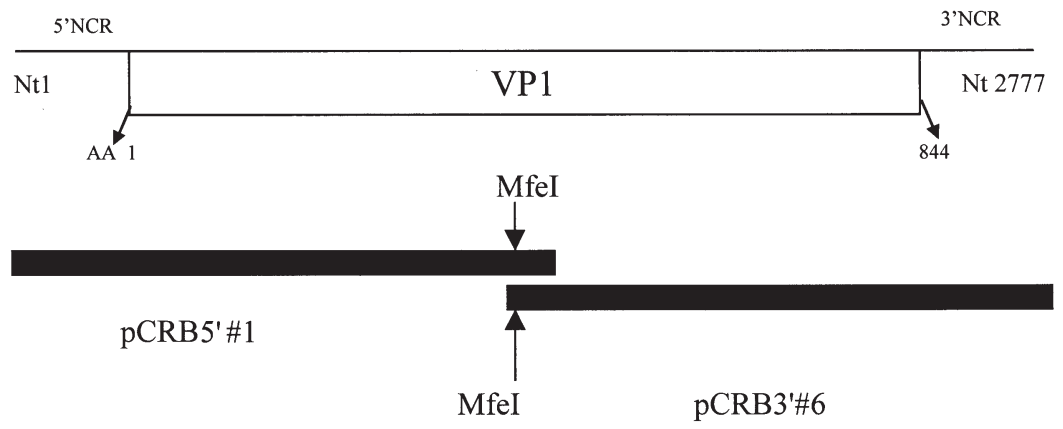

Fig. 1. Construction of 5'- and 3'-overlapping cDNA clones of IPNV Segments A and B, showing gene structure of IPNV Segments $\mathrm{A}$ and $\mathrm{B}$ their encoded proteins (including putative $25 \mathrm{kDa}$ protein). Overlapping cDNA segments of IPNV were generated by RTPCR and the products cloned into a pCR 2.1 vector to obtain various plasmids, as indicated. Restriction enzymes KpnI and Mfe I were used to construct full-length cDNA clones of Segments A and B, respectively. NCR: noncoding regions; Nt: nucleotide; AA: amino acids

wise treated in the same manner. Prior to challenge, the fish were not fed for $1 \mathrm{~d}$. The water level in the tanks was reduced from 100 to $30 \mathrm{l}$ and the water flow was stopped for $3 \mathrm{~h}$. During this period the water was aerated. Freshly prepared culture supernatants of the IPNV isolates at a challenge dose of $1 \times 10^{5}$ plaqueforming units (PFU) $\mathrm{ml}^{-1}$ water were added to the tanks. After $3 \mathrm{~h}$, the water flow was resumed. Mortality was monitored for $36 \mathrm{~d}$ and 10 dead fish from each group were analyzed for the presence of IPNV by titration of head-kidney homogenates on CHSE cells.

Fry challenge. The experiment was run at the VESO Vikan AkvaVet facility, Namsos, Norway. Atlantic salmon fry with an average weight of $0.2 \mathrm{~g}$ were challenged with the second passage from infected CHSE cells of 3 different Sp isolates. Challenge was performed in freshwater by immersion in six 10 l tanks, with 100 fish in each tank and 2 duplicates for each isolate. The waterquality parameters were maintained at optimum levels and the experiment was run at $12 \pm 1^{\circ} \mathrm{C}$. Groups of fish were challenged with Sp103, Sp116 or Sp122 virus, and a group of fish to be used as a control was not challenged but otherwise treated identically to the others. Prior to challenge, the fish were not fed for $1 \mathrm{~d}$. The water level in the tanks was reduced from 10 to $4 \mathrm{l}$ and the water flow was stopped for $5 \mathrm{~h}$. During this period the water was aerated. Freshly prepared culture supernatants of the IPNV isolates at a challenge dose of $1 \times 10^{4} \mathrm{PFU} \mathrm{ml}$ water were added to the tanks. After $5 \mathrm{~h}$, the water flow was resumed. Mortality was monitored for $57 \mathrm{~d}$ and the first 10 dead fish in each tank were analyzed for the presence of IPNV by immunohistochemistry.

Cloning and sequencing of Genomic Segments A and B. Total viral RNA was extracted from the purified virus by treating with Proteinase $K$, as described by Sambrook et al. (1989). Briefly, the pelleted virus was suspended in a reaction buffer containing $100 \mathrm{mM}$ Tris-HCl (pH 7.5), 12 mM EDTA, $150 \mathrm{mM} \mathrm{NaCl}$ and $1 \%$ sodium dodecyl sulfate (SDS), and digested with proteinase $\mathrm{K}\left(200 \mu \mathrm{g} \mathrm{ml}^{-1}\right.$ final concentration) for $3 \mathrm{~h}$ at $37^{\circ} \mathrm{C}$. The genomic RNA was recovered after phenol/ chloroform extraction and ethanol precipitation.

Using genomic RNA as a template, desired overlapping cDNA fragments of Segments A and B were reverse-transcribed, and amplified according to the supplier's protocol (RNA PCR KIT, Perkin-Elmer). The cDNA clones containing the entire coding and noncoding regions of Genomic Segments A and B of these 3 isolates were prepared using standard cloning procedures and methods previously described by Sambrook et al. (1989) and Yao \& Vakharia (1998) (Fig. 1). Several primers were synthesized and employed in RT-PCR 
Table 1. Oligonucleotides used for construction of overlapping cDNA clones of IPNV Genomic Segments A and B and mutant clones of segment showing composition and locations of oligonucleotide primers used for cloning. T7 promoter sequences are italicized, virus-specific sequences are underlined, and restrictions sites are in bold. Orientation of virus-specific sequence of the primer is shown as sense (+) or antisense (-). Positions where the primers bind (nucleotide number) are in accordance with published sequence for West Buxton strain (Yao \& Vakharia 1998)

\begin{tabular}{|lllc|}
\hline Nucleotide sequence & Orientation & \multicolumn{1}{c|}{ Designation } & Nucleotide no. \\
\hline TAATACGACTCTATAGGAAAGAGATTTCAACG & + & A-FA5'NC & $1-18$ \\
GGCCATGGAGTGGTACCTTC & - & A-SpAKpnR & $1584-1603$ \\
GAAGGTACCACTCCATGGCC & + & A-SpAKpnF & $1584-1603$ \\
AAAGCTTCTGCAGGGGGCCCCCTGGGGGC & - & A-SpAPstR & $3081-3097$ \\
TAATACGACTCACTATAGGAAACAGTGGGTCCAACG & + & B-FB5'NC & $1-19$ \\
GTTGATCCCCGTCTTTCTTCG & - & B-SpBIR & $1622-1643$ \\
CTTCCTCAACAACCATCTCATG & + & B-SpBIF & $1529-1550$ \\
AAGATCTGGGGTCCCTGGCGAAC & - & B-FB3'NC & $2767-2783$ \\
CCATATGCGGTGTGAAATACCG & + & pUC19-pUCNdeF & $482-503$ \\
CTTTCGCGTCGACGGAGAG & - & A-SpA68mR & $58-77$ \\
CTCTCCGTCGACGGCGAAAG & + & A-SpA68mF & $58-77$ \\
CTCCTTGGTCACCAGCT & - & A-BstER & $582-599$ \\
GTTTGTTCGTCTTGCATTG & + & A-SpA119mR & $110-130$ \\
CAATGCAAGACGAACACAAAC & - & A-SpA119mF & $110-130$ \\
\hline
\end{tabular}

amplifications (Table 1). We used 2 primer pairs, FA5'NC and SpAKpnR, and SpAKpnF and SpAPstR, for RT-PCR amplification of Segment A. Similarly 2 primer pairs, FB5'NC and SpBIR, and SpBIF and FB3'NC, were used for preparing cDNA clones of Segment B. Amplified fragments were cloned into the ECoRI site of pCR2.1 vector using 'TOPO TA' cloning kit (Invitrogen). At least 3 independent $5^{\prime}$-end and 3 '-end clones of Segments A and B for all isolates were sequenced.

The cDNA clones in all these plasmids were sequenced by the dideoxy chain termination method with an Applied Biosystem automated DNA sequencer, and the sequence data were analyzed by using PC/GENE (Intellegenetics) software. A phylogenetic analysis of all the isolates was carried out using the CLUSTAL program of PC/GENE software.

Site-directed mutagenesis. To construct mutant cDNA clone of Segment A lacking the first initiation codon at Nucleotide Position 68, 2 primer pairs were synthesized and used for PCR amplification of parent plasmid pUC19122A. These primer pairs, pUCNdeF plus SpA68mR (Nucleotide Positions 58 to 77 of Segment A) and SpA68mF plus BstER (Positions 582 to 599 of Segment A) yielded DNA fragments of 307 and $541 \mathrm{bp}$, respectively. These fragments were combined and subsequently amplified by PCR, using the flanking primers (pUCNdeF and BstER) to produce an $848 \mathrm{bp}$ fragment. This fragment was cloned into a pCR2.1 vector (Invitrogen) to obtain plasmid pCR68m. This plasmid was digested with NdeI and BstEII, and the resulting fragment was cloned into appropriately cleaved pUC19122A. Finally, the mutant clone of
Segment A, SpA68m, was obtained in which the initiation codon ATG was mutated to ACG. A similar approach was used to construct the mutant cDNA clone SpA119m, in which the second initiation codon at Nucleotide Position 119 was mutated to ACG. The 2 primer pairs used to make this construct were pUCNdeF plus SpA119mR, and SpA119mF plus BstER.

In vitro transcription, translation and immunoprecipitation analysis. In vitro transcription and translation reactions were performed using the 'TNTQuick Coupled Transcription-Translation System' (Promega), as described by the manufacuturer. Briefly, the DNA template $(2 \mu \mathrm{g})$ was added to a tube containing TNT buffer, $\left[{ }^{35} \mathrm{~S}\right]$-labeled methionine, amino acids mixture (minus methionine), distilled water, rabbit reticulocyte lysate, and T7 polymerase. The mixture was incubated at $30^{\circ} \mathrm{C}$ for $90 \mathrm{~min}$. An aliquot of $15 \mu \mathrm{l}$ was withdrawn, diluted with $135 \mu \mathrm{l}$ of wash buffer $(0.15 \mathrm{M} \mathrm{NaCl}, 0.005 \mathrm{M}$ EDTA, $0.05 \mathrm{M}$ Tris- $\mathrm{HCl}, \mathrm{pH} 8.2,0.05 \% \mathrm{NP} 40$ ), and then $103 \mu \mathrm{l}$ of washed PANSORBIN cells suspension (Calbiochem) was added. The mixture was incubated at room temperature for $15 \mathrm{~min}$ and the cells were removed by centrifugation. Seventy $\mu$ l of polyclonal rabbit antiIPNV serum (1:10 dilution with water) was added and the mixture was kept at room temperature for 2 to $3 \mathrm{~h}$. The antigen-antibody complexes were precipitated with PANSORBIN cells $(96 \mu \mathrm{l})$ by incubating at room temperature for $15 \mathrm{~min}$. After washing 3 times, the pellets were resuspended in $50 \mu \mathrm{l}$ of sample buffer (125 mM Tris-HCl pH 6.8, 2\% SDS, $10 \%$ glycerol, $0.5 \% \quad \beta$-mercaptoethanol and $0.002 \%$ bromophenol blue) and heated at $100^{\circ} \mathrm{C}$ for $5 \mathrm{~min}$. After 


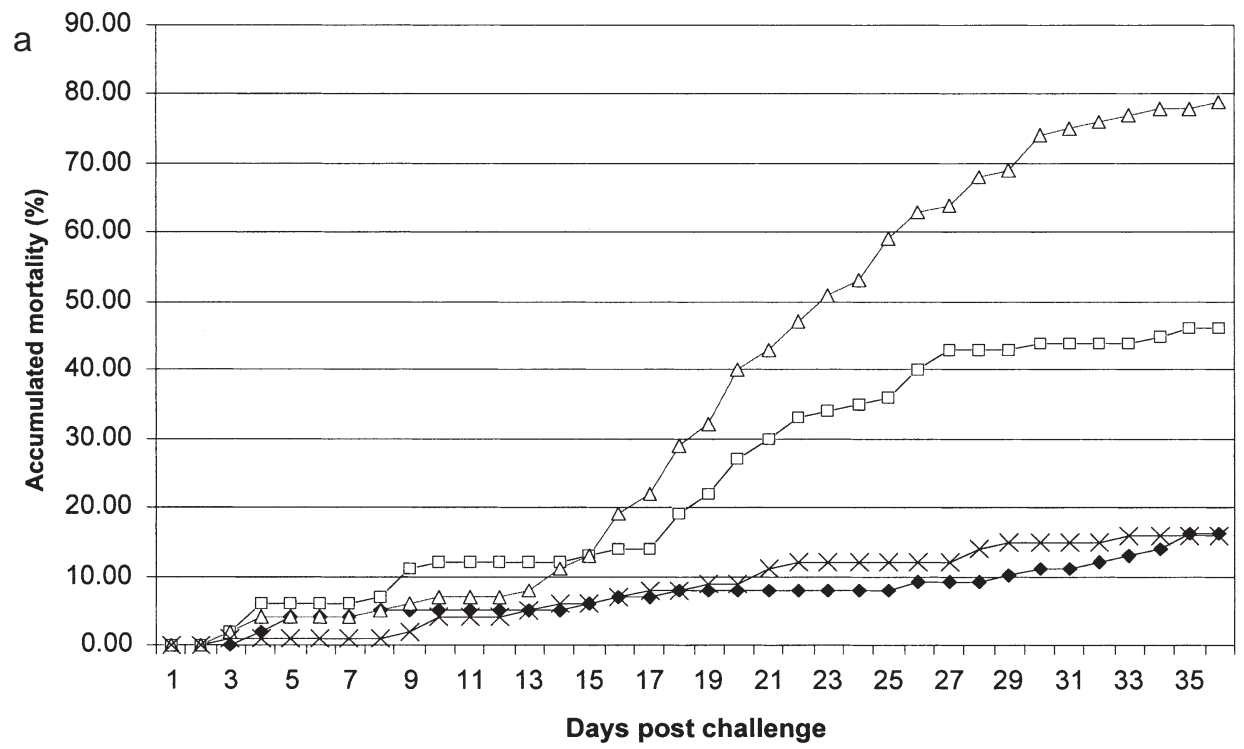

b

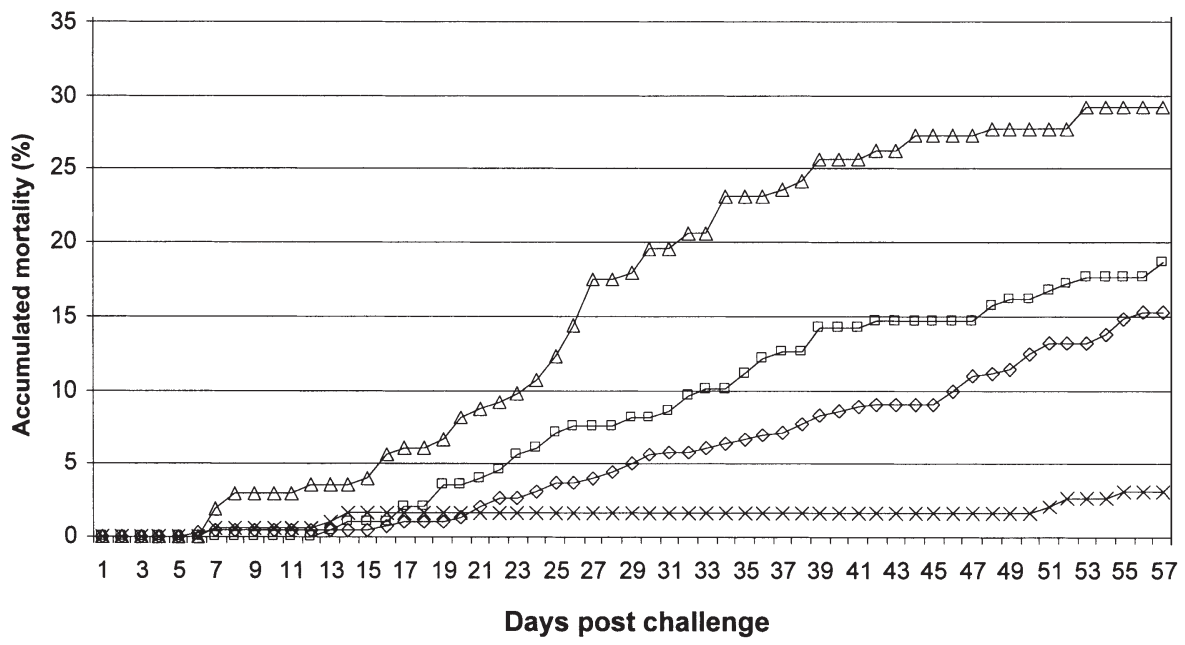

Fig. 2. Salmo salar. Percentage cumulative mortality rates of (a) post-smolts and (b) fry challenged with different Sp strains of

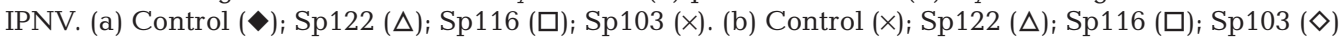

centrifugation at $12000 \times g$ for $5 \mathrm{~min}$, the supernatant was removed and subjected to $12.5 \%$ SDS-polyacrylamide gel electrophoresis (PAGE). The gel was fixed with a mixture of $30 \%$ methanol and $8 \%$ acetic acid for 30 min followed by $\mathrm{EN}^{3} \mathrm{HANCE}$ solution (Biotechnology Systems NEN Research Products) for $45 \mathrm{~min}$, dried and exposed to film overnight at $-70^{\circ} \mathrm{C}$ for autoradiography. The film was developed using an automated film processor (Kodak XR-2).

Nucleotide sequence accession numbers. The complete nucleotide and deduced amino acid sequences of IPNV Genome Segments A and B of the Sp103, Sp116 and Sp122 strains have been deposited in the GenBank under Accession Nos. AY354519, AY354520, AY354521, AY354522, AY354523 and AY354524.

\section{RESULTS AND DISCUSSION}

\section{Mortality of Atlantic salmon fry and post-smolts}

To study the molecular basis of virulence in IPNV of the Sp serotype, 3 field isolates were selected from field outbreaks of IPN in NW Norway in 1998, and used for challenge. Fig. 2a shows the percentage cumulative mortality rate in Atlantic salmon postsmolts challenged with Sp103, Sp116 and Sp122 isolates. Of these 3 isolates, Sp122 produced the highest mortality rate of $79 \%$, followed by Sp116, which caused $46 \%$ cumulative mortality at $36 \mathrm{~d}$ post-challenge. Sp103 isolate was rather avirulent and caused only a $16 \%$ mortality rate, which was about the same 


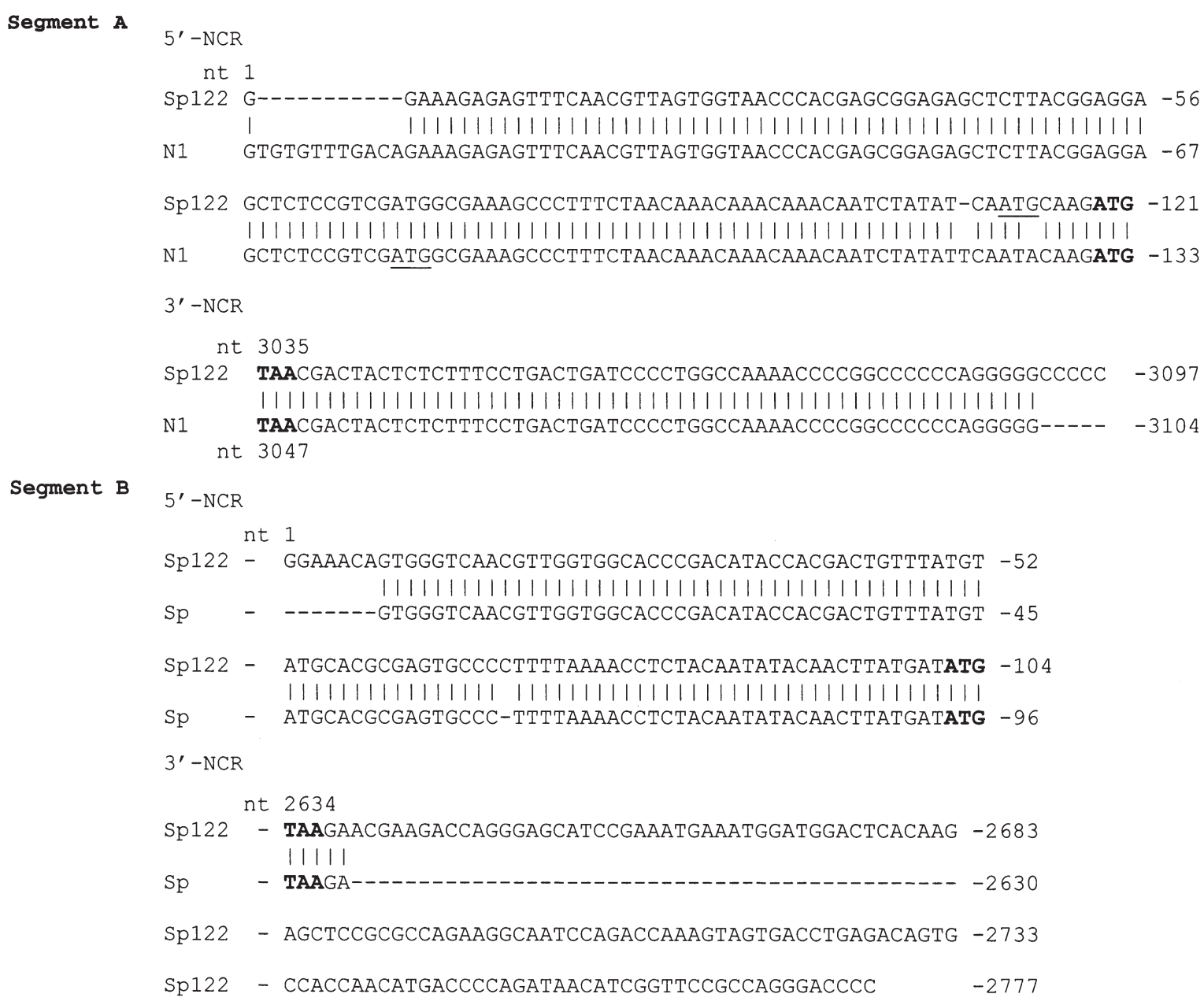

Fig. 3. Nucleotide sequence comparison of 5'- and 3'-noncoding regions (NCR) of Segments A and B of IPNV Strains Sp122, N1 and SpD. Start and stop codons of major ORFs of Segments A and B are in boldface, and start codon of small ORF (NS protein, VP5) is underlined. (I) nucleotide identity; (-) deletions of residues; nt: nucleotide

as in the unchallenged control group. The relatively high background mortality was due to the fact that some of the fish were poorly smoltified, which made them non-tolerant to seawater. The virus was readily isolated from the respective challenged fish, whereas no virus could be isolated from unchallenged fish.

A comparable mortality rate was observed in fry of Atlantic salmon challenged with the same isolates. Fig. $2 b$ shows the mean percentage cumulative mortality rate of 2 duplicate tanks. Although the cumulative mortality did not reach the same level as for the smolt experiment, again Sp122 produced the highest mortality rate of $29.3 \%$, followed by Sp116 with $18.9 \%$ and Sp103 with $15.3 \%$ cumulative mortality. In this experiment, the control group exhibited a mortality rate of only $3.1 \%$, which is considered normal background mortality at this fish size. The 2 fish trials together strongly suggest that the observed differences in virulence between the 3 isolates in Atlantic salmon of different physiological maturity are genuine. In earlier studies, Dorson \& Torchy (1981) reported a similar mortality trend in rainbow trout fry; however, the molecular characterization of their viruses was not achieved.

\section{Sequence analysis of IPNV genome}

To molecularly characterize these Sp isolates, we determined the complete nucleotide sequences of IPNV Genome Segments A and B, including the precise 5'and 3 '-terminal sequences. Segment A is $3097 \mathrm{bp}$ long and contains 3 overlapping ORFs. The major ORF encodes the VP2-VP4-VP3 polyprotein, whereas the other 2 overlapping frames encode a 12 to $15 \mathrm{kDa}$ nonstructural protein (NS) and a putative $25 \mathrm{kDa}$ NS protein (Fig. 1). Segment B is 2777 bp long and encodes 
VP1, the RNA-dependent RNA polymerase. To the best of our knowledge, this is the first report of the fulllength nucleotide sequences of the Sp serotype. Fig. 3 compares the available terminal sequences of Segment A (N1 strain, an Sp serotype: GenBank Accession No. D00701) and Segment B (Sp strain, Dobos's laboratory: GenBank Accession No. M58757) with those of the Sp122 strain, and reveals some notable differences. For example, in Segment A of the N1 strain, there are 11 additional residues from Positions 2 through 12, which are absent from $3 \mathrm{Sp}$ strains sequenced here, as well as from Jasper (GenBank Accession No. M18049) and West Buxton (GenBank Accession No. AF078668). Since the terminal sequences of IPNV are highly conserved, these N1 residues may not exist (Yao \& Vakharia 1998). Secondly, there is an addition of a $T$ residue after Position 109 and the last 5 conserved $C$ residues are missing. In Segment B of the Sp strain, the first 7 residues of the $5^{\prime}$-end and the last 139 residues of the 3 '-end were not determined, and there is a deletion of a $\mathrm{C}$ residue at Position 69 (Fig. 3).

\section{Initiation of translation of major ORF in Segment A}

Comparison of the nucleotide sequence of $3 \mathrm{Sp}$ strains sequenced in our laboratory with that of N1 strain (also Sp serotype) revealed the presence of an initiation codon at Position 68 in Sp strains for the translation of polyprotein, followed by a second inframe codon at Position 119 due to deletion of a residue after Position 109 (see Fig. 3). To determine which start codon is used to translate the polyprotein VP2-VP4VP3, we made 2 mutant cDNA clones using sitedirected mutagenesis (SpA68m and SpA119m), whereby the ATG codon was mutated to ACG. After in vitro transcription and translation of the parent and the mutant clones, the translated protein products were immunoprecipitated with rabbit anti-IPNV polyclonal antibody and fractionated by SDS-PAGE (Fig. 4). Our results show that the mobility of the proteolytically processed IPNV proteins derived from the parent pUC19SpA clone (Lane 1) was identical to the proteins derived from the mutant SpA68m clone (Lane 2), indicating that the translation of the polyprotein is initiated at the second in-frame start codon at Position 119. To our surprise, the mutant clone pSpA119m also yielded protein products (Lane 3); however, the pVP2 protein was slightly smaller than the pVP2 protein derived from pUC19SpA and SpA68m clones. These results suggest that the translation of the polyprotein is not initiated at the first start codon at Position 68.

If the translation of the polyprotein had initiated at the first start codon at Position 68, it would have yielded a pVP2 protein, which would have been approximately

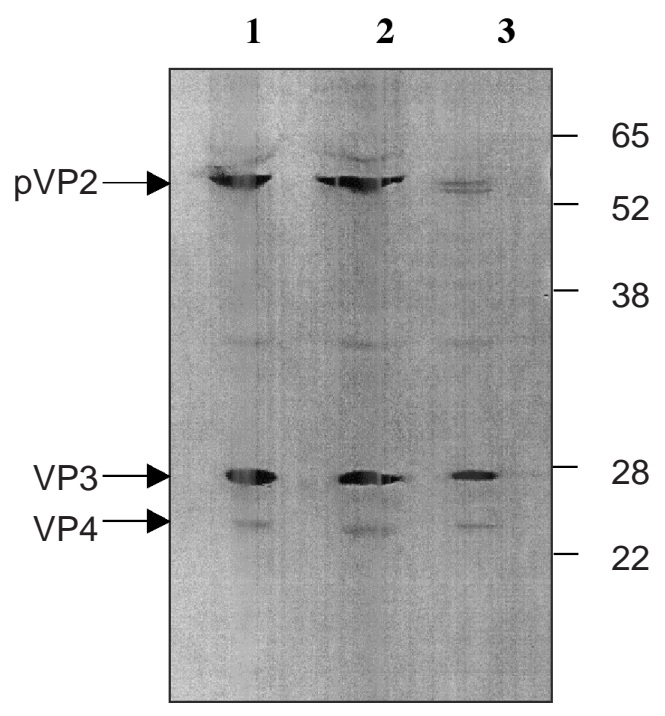

Fig. 4. Fractionation of [ $\left.{ }^{35} \mathrm{~S}\right]$-labeled IPNV proteins by $12.5 \%$ SDS-PAGE. Full-length cDNA clones of IPNV Segment A were transcribed and translated in rabbit reticulocyte lysate system, and translated protein products were immunoprecipitated using anti-IPNV serum. Lane 1: protein products derived from parent clone pUC19SpA; Lane 2: protein products obtained from mutant clone SpA68m $\left({ }^{68} \mathrm{ATG}-\mathrm{ACG}\right)$; and Lane 3: proteins derived from the mutant clone SpA119m $\left({ }^{119} \mathrm{ATG}-\mathrm{ACG}\right)$. Molecular weight markers $(\mathrm{kDa})$ shown on the right, IPNV protein designations on left

$2 \mathrm{kDa}$ greater in size than the authentic $\mathrm{pVP} 2$. Instead, it gave a pVP2 protein product that was truncated by about $1.5 \mathrm{kDa}$. Careful examination of the nucleotide sequence revealed the presence of an in-frame start codon at Position 161, which would give rise to a truncated pVP2 protein (by 14 amino acids). Although the efficiency of the in vitro translation and proteolytic processing of the polyprotein from this construct was not altered, the truncated pVP2 protein could not be efficiently immunoprecipitated, possibly due to a change in conformation of the protein and loss of some antigenicity.

\section{Molecular characterization of IPNV isolates}

To identify putative amino acids involved in the virulence of IPNV-Sp, we compared the deduced amino acid sequences of these 3 isolates. Table 2 shows the location of amino acid changes in the proteins encoded by Segments A and B. There are a total of 8 amino acid substitutions in Segment A between these 3 isolates, of which 6 are located in VP2 and 2 in VP3. Sp122, which is the most virulent isolate, has 5 unique amino acid substitution at Positions 199, 217, 221, 247 and 500. Surprisingly, Sp116 and Sp103 are quite similar despite the observed difference in virulence, and only have unique substitutions at Position 288, and in VP3 
Table 2. Location of amino acid changes in proteins encoded by Segments A and B of 3 Sp serotype strains of IPNV: 6 amino acid substitutions occurred in VP2 region (Residues 1 to 508), none in VP4 (Residues 509 to 734), 2 in VP3 (Residues 735 to 972), and 5 in VP1 (encoded by Segment B; Residues 1 to 844)

\begin{tabular}{|lcccccccc|}
\hline Viruses & \multicolumn{7}{c|}{ Amino acid change (position) } \\
\hline Segment A & 199 & 217 & 221 & 247 & 288 & 500 & 883 & 968 \\
Sp122 & Thr & Thr & Thr & Thr & Val & Tyr & Asn & Asp \\
Sp103 & Ile & Pro & Ala & Ala & Val & His & Tyr & Asp \\
Sp116 & Ile & Pro & Ala & Ala & Ala & His & Asn & Asn \\
& & & & & & & & \\
Segment B & 125 & 154 & 187 & 240 & 690 & & & \\
Sp122 & Ile & Thr & Pro & His & Phe & & & \\
Sp103 & Met & Ile & Pro & Arg & Phe & & & \\
Sp116 & Ile & Thr & His & His & Leu & & & \\
\hline
\end{tabular}

U56907; SpAL (Leong), GenBank Accession No. U48225; Sp (Dobos), GenBank Accession No. M58757. Comparison of the Sp103 isolate with those of strains N1, Sp, SpAT and SpAL Segment A showed 99.0, 98.5, 98.4 and $97.5 \%$ identity at the nucleotide level and 99.2, 99.0, 98.9 and 97.1\% identity at the amino acid level, respectively. For Segment B, the nucleotide and amino acid identity with that of strain Sp was 98.5 and $98.3 \%$, respectively. A phylogenetic analysis, based on the deduced amino acid sequences of Segment A of the Sp strains, revealed 2 distinct groups (Fig. 5). The first group consisted of all Norwegian at Positions 968 and 883, respectively. Taken together, these findings point toward residues at Positions 199, 217, 221, 247 and 500 explaining the variation in IPNV virulence, but a definite conclusion cannot be drawn based on VP2 results alone. There are 5 amino acid substitutions in the VP1 protein encoded by Segment B. Sp122 and Sp116 differ from the avirulent Sp103 isolate at Positions 125, 154 and 240. Since Sp122 and Sp116 isolates cause mortality and have quite similar VP1 sequences, it is quite possible that VP1 may have a role in the virulence of IPNV.

The nucleotide and deduced amino acid sequences of the representative Sp103 isolate were compared with the available complete sequences of Segments A and B of Sp strains: N1 strain, GenBank Accession No. D00701; Sp (Nicholson), GenBank Accession No. AF342728; SpAT (Taiwan), GenBank Accession No.

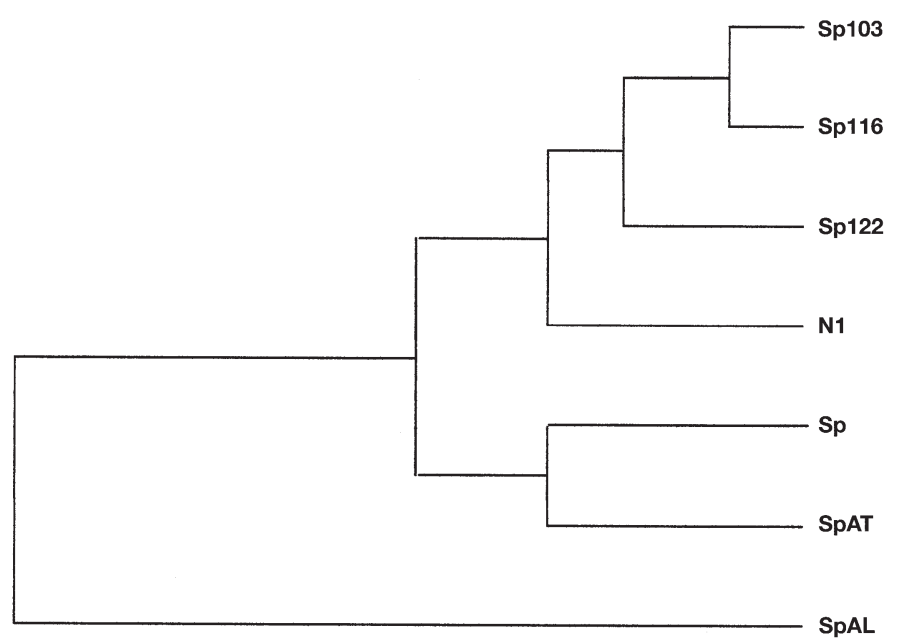

Fig. 5. Dendrogram alignment of structural proteins encoded by Segment A of various IPNV-Sp isolates using CLUSTAL program of PC/GENE software (Intellegenetics). Sp103, Sp116, Sp122, N1: Norwegian isolates; Sp, SpAL: US isolates; SpAT: Taiwanese isolate strains obtained from Atlantic salmon, namely N1 that was isolated in the late 1980s and other 3 isolated in the late 1990s. The second group comprised all US or Taiwanese strains obtained from rainbow trout, which are not as virulent as the Norwegian isolates. Interestingly, in a recent study conducted by our group, the virulent isolate Sp122 did not cause any mortality in rainbow trout fry. This suggests that virulence may not be directly correlated in different species and/or the virus may have lost its virulence after passage in cell culture (Silim et al. 1982, McAllister \& Owens 1986).

Our results indicate that the molecular determinants of IPNV virulence reside in Segment A, especially in the VP2 region. This result is also in accordance with that of Sano et al. (1992), who generated reassortants between virulent and avirulent strains of 2 different serotypes and demonstrated that the virulence of IPNV is associated with Segment A. Similarly, Bruslind \& Reno (2000) found 2 amino acid differences in the VP2 at Positions 217 and 286 between the virulent and avirulent Buhl-subtype isolates of IPNV. VP2 is a major capsid protein and is responsible for the production of type-specific monoclonal antibodies (Nicholson 1993). The residues, which fall within the VP2 region, can possibly alter the properties of this protein. To which extent this correlates with the virulence between these closely related isolates is not known. Another point is that these changes could influence the antigenic properties of VP2. For example, in infectious bursal disease virus (IBDV), another member of the Birnaviridae family, it was shown that substitution of a few residues in VP2 of IBDV resulted in a variant field isolate that could cause disease in immunized chickens (Lana et. al 1992). Furthermore, the molecular basis of virulence was detershown that residues at Positions 253, 279 and 284 of VP2 are involved in virulence, cell tropism and pathogenic phenotype of IBDV (Brandt et al. 2001). mined using the reverse-genetics system, and it was 


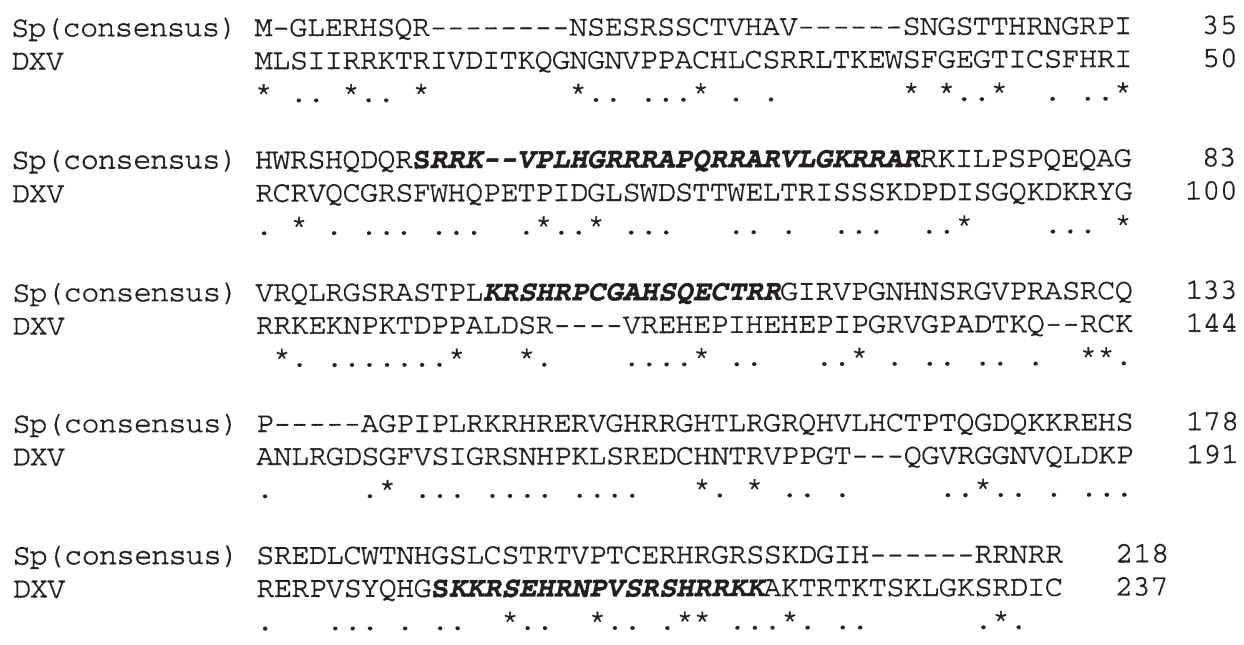

Fig. 6. Alignment of deduced amino acid sequence of putative $25 \mathrm{kDa}$ protein of Sp isolates of IPNV (consensus) and $27 \mathrm{kDa}$ protein of Drosophila X virus (DXV). Potential bipartite nuclear targeting sequences in IPNV (Residues 46 to 71 and 97 to 113 ) and DXV (Residues 203 to 221) are in boldface type and italicized. *: amino acid identity; dots: similarity; -: deletions of residues

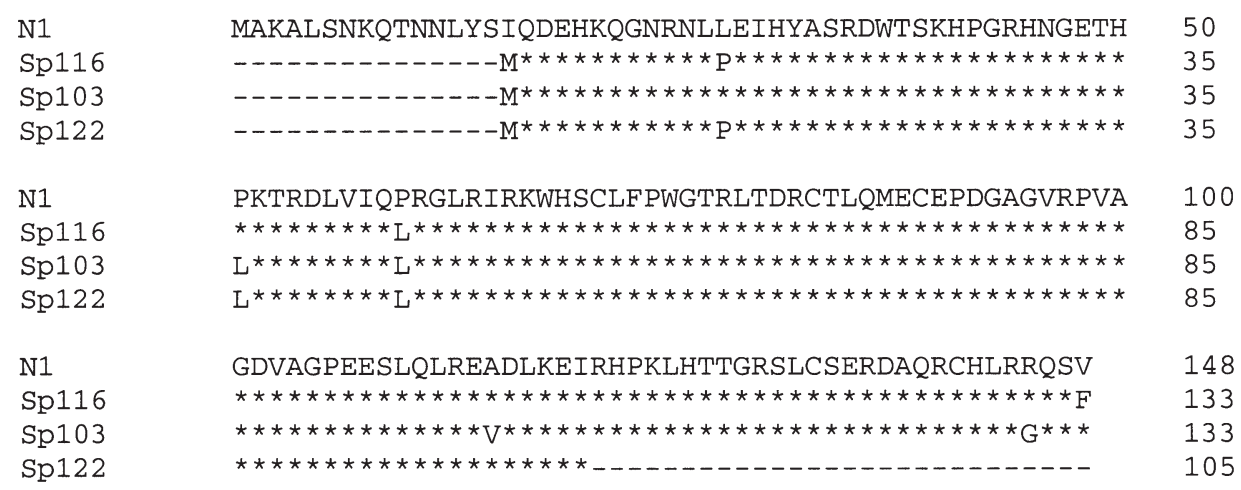

Fig. 7. Comparison of deduced amino acid sequence of 12-17 kDa nonstructural protein of IPNV-Sp strains. *: amino acid identity; -: deletions of residues

The sequence analysis of $7 \mathrm{Sp}$ isolates also revealed a very interesting finding of a possible putative ORF in Segment A encoding a $25 \mathrm{kDa}$ protein (Fig. 6). This ORF is only detected in Sp strains of IPNV and has not been reported so far. An analogous putative $27 \mathrm{kDa}$ protein is also present in Drosophila X virus (DXV), another birnavirus of Entemobirnavirus genus (Chung et al. 1996). This $25 \mathrm{kDa}$ protein has $12.7 \%$ identity with and $44.7 \%$ similarity to the DXV protein. These proteins contain 2 basic, arginine-rich, bipartite nuclear targeting sequences (NLS) (boldface italics in Fig. 6), which we believe may have a function of targeting proteins to the nucleus. In dengue virus, NLS protein with nuclear localization sequence has been shown to target proteins (beta-galactosidase) to the nucleus (Forwood et al. 1999). However, we have no evidence as to whether this putative $25 \mathrm{kDa}$ ORF is expressed by the Sp strain of IPNV. Efforts are under way in our laboratory to produce antiserum against this putative protein in order to detect its presence in infected cells.
Previous studies have shown that Segment A of IPNV also encodes a $17 \mathrm{kDa}$ arginine-rich NS protein (VP5) from a small ORF that precedes and partially overlaps the polyprotein ORF (Magyar \& Dobos 1994). This protein can be detected only in infected cells and is not present in the virion. A similar NS protein, which is not required for replication but plays an important role in pathogenesis, has been reported in IBDV (Yao et al. 1998). In this study, we found that the NS protein exists in different forms in $\mathrm{Sp}$ and other serotypes. This polypeptide, which is normally 148 amino acids long (17 $\mathrm{kDa}$ ), is truncated and of varying lengths within the Sp serotype (Fig. 7). Since there was a deletion of a nucleotide residue after Position 109 in the Sp isolates sequenced here, there was a frame shift in the ORF encoding the NS protein compared with the sequence of Strain N1 (see Fig. 3). Therefore, the translation of this protein could only be initiated at the start codon (underlined in Fig. 3) at Nucleotide Position 112 to yield a $15 \mathrm{kDa}$ protein. However, in case of the virulent Sp122 
isolate, there is a premature stop codon at Position 427 that could yield a truncated protein of $12 \mathrm{kDa}$. For the VR299 strain of IPNV, it was convincingly shown by Weber et al. (2001) that the expression of the NS protein (VP5) is initiated at the second in-frame start codon at Nucleotide Position 113 and not 68, yielding a protein of $15 \mathrm{kDa}$. In addition, it was shown that this protein is dispensable for the replication of IPNV. Because the NS protein contains $\mathrm{Bcl}-2$ homologue domains, and expression of this protein in CHSE cells enhances cell viability during IPNV infection (Hong et al. 2002), we suspect that it may play an important role in IPNV-induced apoptosis. This could be ascertained using the reverse-genetics approach developed for IPNV (Yao \& Vakharia 1998).

Acknowledgements. We thank Gerard H. Edwards for technical assistance. This work was supported in part by a fellowship to R.B.S. from Alpharma, Animal Health Division, Norway, and a grant from the US Department of Agriculture (NRICGP 00-02075) to V.N.V.

\section{LITERATURE CITED}

Brandt M, Yao K, Liu M, Heckert RA, Vakharia VN (2001) Molecular determinants of virulence, cell tropism, and pathogenic phenotype of infectious bursal disease virus. J Virol 75:11974-11982

Bruslind LD, Reno PW (2000) Virulence comparison of three buhl-subtype isolates of infectious pancreatic necrosis virus in brook trout fry. J Aquat Anim Health 12:301-315

Calvert JG, Nagy E, Soler M, Dobos P (1991) Characterisation of the VPg-dsRNA linkage of infectious pancreatic necrosis virus. J Gen Virol 72:2563-2567

Chang N, MacDonald, RD, Yamamoto T (1978) Purification of infectious pancreatic necrosis (IPN) virus and comparison of peptide composition of different isolates. Can J Microbiol 24:19-27

Christie KE (1997) Immunization with viral antigens; infectious pancreatic necrosis. Dev Biol Stand 90:191-199

Chung HK, Kordyban S, Cameron L, Dobos P (1996) Sequence analysis of the bicistronic Drosophila X virus genome Segment A and its encoded polypeptides. Virology 225:359-368

Dobos P (1976) Size and structure of the genome of infectious pancreatic necrosis virus. Nucleic Acids Res 3:1903-1919

Dobos P (1995a) The molecular biology of infectious pancreatic necrosis virus (IPNV). Annu Rev Fish Dis 5:24-54

Dobos P (1995b) Protein-primed RNA synthesis in vitro by the virion associated RNA polymerase of infectious pancreatic necrosis virus. Virology 208:19-25

Dorson M, Torchy C (1981) The influence of fish age and water temperature on mortalities of rainbow trout, Salmo gairdneri Richardson, caused by a European strain of infectious pancreatic necrosis virus. J Fish Dis 4:213-221

Duncan R, Dobos P (1986) The nucleotide sequence of infectious pancreas necrosis virus (IPNV) dsRNA Segment A reveals one large ORF encoding a precursor polyprotein. Nucleic Acids Res 14:5934

Duncan R, Nagy P, Krell J, Dobos P (1987) Synthesis of the infectious pancreatic necrosis virus polyprotein, detection of a virus-encoded protease, and fine structure mapping of genome Segment A coding regions. J Virol 61:3655-3664
Duncan R, Mason CL, Nagy E, Leong JA, Dobos P (1991) Sequence analysis of infectious pancreatic necrosis virus genome Segment B and its encoded VP1 protein: a putative RNA-dependent RNA polymerase lacking the GlyAsp-Asp motif. Virology 181:541-552

Forwood JK, Brooks A, Briggs LY, Xiao CY, Jans DA, Vasudevan SG (1999) The 31-amino-acid interdomain dengue virus NS5 protein contains a functional NLS and inhibitory CK2 site. Biochem Biophys Res Commun 257:731-737

Hill BJ, Way K (1995) Serological classification of infectious pancreatic necrosis (IPN) virus and other aquatic birnaviruses. Annu Rev Fish Dis 5:55-77

Hong JR, Gong HY, Wu JL (2002) IPNV VP5, a novel antiapoptosis gene of the Bcl-2 family, regulates Mcl-1 and viral protein expression. Virology 295:217-229

Knott RM, Munro AL (1986) The persistence of infectious pancreatic necrosis virus in Atlantic salmon. Vet Immunol Immunopathol 12:359-364

Lana DP, Beisel CE, Silva RF (1992) Genetic mechanisms of antigenic variation in infectious bursal disease virus: analysis of a naturally occurring variant virus. Virus Genes 6:3 247-259

Leong JC, Fryer JL (1993) Viral vaccines for aquaculture. Annu Rev Fish Dis 3:225-240

Leong JC, Brown D, Dobos P, Kibenge FSB, Ludert JE, Müller H, Mundt E, Nicholson BL (2000) Family Birnaviridae. Virus taxonomy: classification and nomenclature of viruses. In: van Regenmortel MHV, Fauquet CM, Bishop DHL, Carstens MK and 7 others (eds) Seventh report of the International Committee on Taxonomy of Viruses. San Diego, Academic Press, p 481-490

Magyar G, Dobos P (1994) Evidence for the detection of the infectious pancreatic necrosis virus polyprotein and the 17 $\mathrm{kDa}$ polypeptide in infected cells and of the NS protease in purified virus. Virology 204:580-589

McAllister PE, Owens WJ (1986) Infectious pancreatic necrosis virus: protocol for a standard challenge to brook trout. Trans Am Fish Soc 115:466-470

Nicholson BL (1993) Use of monoclonal antibodies in identification and characterization of fish viruses. Annu Rev Fish Dis $241-257$

Petit S, Lejal N, Huet J, Delmas B (2000) Active residues and viral substrate cleavage sites of the protease of the birnavirus infectious pancreatic necrosis virus. J Virol 74:2057-2066

Sambrook J, Fritsch EF, Maniatis T (1989) Molecular cloning: a laboratory manual, 2nd edn. Cold Spring Harbor Laboratory, Cold Spring Harbor, NY

Sano M, Kamato N, Fukuda H, Saneyoshi M, Sano T (1992) Virulence of infectious pancreatic necrosis virus is associated with the larger RNA segment (RNA Segment A). J Fish Dis 15:283-293

Silim A, Elazhary MASY, Lagace A (1982) Susceptibility of trouts of different species and origins to various isolates of infectious pancreatic necrosis virus. Can J Fish Aquat Sci 39:1580-1584

Weber S, Fichtner D, Mettenleiter TC, Mundt E (2001) Expression of VP5 of infectious pancreatic necrosis virus strain VR299 is initiated at the second in-frame start codon. J Gen Virol 82:805-812

Wolf K (1988) Fish viruses and fish viral diseases. Comstock Publishing Associates, Cornell University Press, Ithaca, NY

Yao K, Vakharia VN (1998) Generation of infectious pancreatic necrosis virus from cloned cDNA. J Virol 72:8913-8920

Yao K, Goodwin MA, Vakharia VN (1998) Generation of a mutant infectious bursal disease virus that does not cause bursal lesions. J Virol 72:2647-2654

Submitted: August 7, 2003; Accepted: April 2, 2004

Proofs received from author(s): September 10, 2004 